\title{
Mechanisms for the release of halogens from sea-salt particles by free radical reactions
}

\author{
Michael Mozurkewich \\ Department of Chemistry and Centre for Atmospheric Chemistry, York University, North York, Ontario, \\ Canada
}

\begin{abstract}
A possible source of gas phase bromine in the Arctic winter and early spring is the sea-salt aerosol. In this paper, chemical mechanisms for the release of photochemically active bromine from sea-salt are examined. The first of these is oxidation of bromide to elemental bromine by peroxymonosulfuric acid (Caro's acid) produced by the free radical chain oxidation of S(IV). The chain reaction could be initiated in the dark by $\mathrm{NO}_{2}$ or, following polar sunrise, by the reaction of ozone with superoxide. Although the yield of Caro's acid at $298 \mathrm{~K}$ is small, the yield may increase at the low temperatures encountered in the Arctic. This could result in the conversion of a large fraction of the initial sea-salt alkalinity to Caro's acid. Caro's acid is known to oxidize bromide to $\mathrm{Br}_{2}$. Since this mechanism requires low temperatures and high $\mathrm{SO}_{2}$ concentrations, it is only effective during the winter and early spring and should not oxidize significant amounts of halides in the global marine boundary layer. A second possible mechanism is the free radical oxidation of aqueous bromide to bromine by $\mathrm{OH}$ and $\mathrm{HO}_{2}$. This may be effective at moderate $\mathrm{pH}$ and may contribute to $\mathrm{Br}$ cycling on a global scale. The evaluation of both mechanisms is highly uncertain because of incomplete physical-chemical data. In addition to these primary release mechanisms, there are possible autocatalytic cycles for the release of bromine from sea-salt. These involve the gas phase production of either BrO or HOBr and the return of these species to the sea-salt particles where they initiate additional oxidation of bromide. The efficiency of these cycles should depend critically on the relative amounts of $\mathrm{HOBr}$ and $\mathrm{HBr}$ produced by the gas phase chemistry. These mechanisms do not appear to be effective as sources of photochemically active $\mathrm{Cl}$.
\end{abstract}

\section{Introduction}

A dramatic loss of surface layer ozone has been observed shortly after polar sunrise in the Arctic [Bottenheim et al., 1990]. This loss is associated with a large increase in the amount of "filterable" Br present in the atmosphere. Barrie ct al. [1988] have proposed that the ozone loss is caused by a catalytic cycle involving $\mathrm{Br}$ atoms. There is also evidence for halogen atom oxidation of hydrocarbons during polar sunrise [Jobson et al., 1994]. It appears that the filterable $\mathrm{Br}$ is inorganic but is not $\mathrm{HBr}$; this implies that it is in a photochemically active form, such as HOBr or $\mathrm{Br}_{2}$ [Li et al., 1994].

Computational studies [Barrie et al., 1988; Mc Connell et al., 1992; Fan and Jacob, 1992] have shown that the observed filterable $\mathrm{Br}$ can produce significant ozone loss if it is in a photochemically active form. Reactions with hydrocarbons eventually convert the active $\mathrm{Br}$ into inactive $\mathrm{HBr}$; the $\mathrm{HBr}$ returns to the particle phase. As a result, these models require a means of recycling $\mathrm{HBr}$ into an active form; a variety of proposals have been made as to how this is accomplished. The models assume an initially high concentration of active gas phase $\mathrm{Br}$.

Copyright 1995 by the American Geophysical Union.

Paper number 94JD00358.

0148-0227/95/94JD-00358505.00
The initial source of the filterable Br has not yet been identified. The air masses do contain particulate $\mathrm{Na}$; this is presumably from sea-salt. However, the $\mathrm{Br} / \mathrm{Na}$ ratios reported by Bottenheim et al. [1990] are typically about a factor of 5 larger than in sea-salt. The Na size distributions imply that the sea-salt aerosol is well aged and that much of the original sea-salt has been lost. This is reasonable since this aerosol must have been transported a substantial distance from open ocean areas. If sea-salt is the original source of the $\mathrm{Br}$, then the lifetime of $\mathrm{Br}$ in the air mass must be much longer than that of sea-salt. This implies that the $\mathrm{Br}$ is efficiently recycled, perhaps by the mechanism of Fan and Jacob [1992]. Here I propose a mechanism by which the bromine is released from seasalt particles shortly after their formation.

The basic features of this mechanism are the following: (1) Gas phase free radicals are efficiently trapped in seasalt aerosol particles. (2) These radicals induce the free radical chain oxidation of dissolved $\mathrm{SO}_{2}$. (3) One product of this chain reaction is peroxymonosulfuric acid, $\mathrm{H}_{2} \mathrm{SO}_{5}$, also known as Caro's acid; this can oxidize bromide ions to hypobromous acid, HOBr. (4) Subsequent reaction of HOBr with bromide ions results in the release of readily photolyzed bromine molecules to the gas phase. (5) In addition, at lower $p H$ where the free radical chain reaction is not effective, radical-radical reactions can directly produce $\mathrm{Br}_{2}$. (6) Finally, the return of $\mathrm{BrO}$ or $\mathrm{HOBr}$ to sea-salt particles can release additional $\mathrm{Br}_{2}$ in a potentially autocatalytic cycle. Steps (5) and (6) may also help to reactivate $\mathrm{Br}$ after it is converted to $\mathrm{HBr}$ by gas phase 
photochemistry. Most of the individual processes have been previously recognized as being important in cloud water chemistry [Jacob, 1986; McElroy, 1986; Chameides and Stelson, 1992] or as a means of recycling $\mathrm{Br}$ in the Arctic [Fan and Jacob, 1992]. However, the potential for these processes to provide an initial source of active $\mathrm{Br}$ has not been recognized.

\section{Release of Halogens from Sea-Salt Particles as a Result of Sulfur Oxidation}

I assume here that the initial release of $\mathrm{Br}$ is from liquid sea-salt aerosol particles. It is reasonable to assume that these particles are liquid rather than crystalline even though the typical temperatures of the Arctic spring (230 to $250 \mathrm{~K}$ ) are below the eutectic point for $\mathrm{NaCl}$ solutions $(252 \mathrm{~K})$. Small droplets have a pronounced tendency to both supercool and become supersaturated. Also, although the absolute humidity of Arctic air is low, the relative humidity, which determines if salt particles will deliquesce, is high. Since the particles are formed as liquid drops, they may well remain liquid throughout their residence time in the atmosphere.

The chemical reactions occurring in sea-salt particles are very different from those occurring in sulfate aerosol particles. For the purpose of the estimates to be made here, I- assume that the sea-salt particles have the same composition as the "low relative humidity" case (80\% $\mathrm{RH})$ of Chameides and Stelson [1992]. This gives an ionic strength of $4.6 \mathrm{M},\left[\mathrm{Na}^{+}\right]=3.6 \mathrm{M},[\mathrm{Br}]=4.7 \times 10^{-3} \mathrm{M}$, and an initial alkalinity of $0.013 \mathrm{M}$. For the present rough calculations, all activity coefficients are set equal to unity. This should not produce excessive errors for neutral and singly charged species. The only doubly charged ion that affects the chemistry considered here is $\mathrm{SO}_{3}{ }^{2}$; the effect of ionic strength on S(IV) equilibria can be accounted for by using the equilibrium constants measured by Millero et al. [1989] in concentrated $\mathrm{NaCl}$ solutions. Although the use of activities would result in more accurate concentrations, the results of rate calculations would not necessarily be improved.

The gas solubilities used here are given in Table 1 , equilibrium constants for rapid liquid phase equilibria are given in Table 2, and liquid phase rate constants are in Table 3. Methods used to estimate temperature dependencies are discussed in Appendix A.

The initial $p \mathrm{H}$ of the droplets should be near that of seawater $(p \mathrm{H}=8)$ because of the presence of dissolved $\mathrm{HCO}_{3}$. The alkalinity, $A$, of the initial drop is given by

$$
A=\left[\mathrm{HCO}_{3}^{-}\right]+2\left[\mathrm{CO}_{3}{ }^{2}\right] .
$$

As $\mathrm{CO}_{2}$ is displaced from the drop by stronger acids, the $p \mathrm{H}$ slowly drops. Under polar sunrise conditions (200 ppt of $\mathrm{SO}_{2}, 240 \mathrm{~K}$ ), $\mathrm{CO}_{2}$ is almost completely displaced from the drops by $\mathrm{SO}_{2}$. The $p \mathrm{H}$ is then controlled by the $\mathrm{S}(\mathrm{IV})$ acid-base equilibria (E18) and (E19). This maintains the $p \mathrm{H}$ near 7. As $\mathrm{SO}_{3}{ }^{2-}$ is oxidized, the speciation among sulfur compounds changes so that

$$
A=\left[\mathrm{HSO}_{3}{ }^{-}\right]+2\left[\mathrm{SO}_{3}{ }^{2-}\right]+2\left[\mathrm{SO}_{4}{ }^{2-}\right]_{\mathrm{ns}}+\left[\mathrm{HSO}_{5}{ }^{-}\right]
$$

The $p \mathrm{H}$ changes very slowly until the initial alkalinity is exhausted. The $p \mathrm{H}$ then drops rapidly as additional acid is produced. Because of the strong dependence of the solubility of S(IV) (i.e., the sum of $\mathrm{SO}_{2}, \mathrm{HSO}_{3}{ }^{-}$, and $\mathrm{SO}_{3}{ }^{2-}$ ) on $\mathrm{pH}$ this produces a substantial change in the liquid phase chemistry.

The amount of time for which the $\mathrm{pH}$ remains high is determined by the rate of oxidation of S(IV). Chameides and Stelson [1992] found that oxidation by ozone, reaction (R1), can exhaust the buffering in a few minutes for conditions typical of the marine boundary layer. Although the rate constant for reaction (R1) is greatly reduced at low temperatures, this is partially compensated for by the increased gas solubilities. As a result, the buffering should be exhausted in a time that is much shorter than the particle lifetime. The uptake of gas phase acids, such as $\mathrm{HNO}_{3}$, should be negligible during this brief initial period.

S(IV) is also oxidized in a free radical chain reaction. This is initiated by reaction of $\mathrm{SO}_{3}{ }^{2-}$ with strongly oxidizing free radicals such as $\mathrm{OH}, \mathrm{Cl}_{2}^{-}$, and $\mathrm{Br}_{2}^{-}$(reactions (R17), (R18), and (R20)). The resulting sulfite radical rapidly adds $\mathrm{O}_{2}$ to form $\mathrm{SO}_{5}$. The chain is propagated via

$$
\begin{aligned}
& \mathrm{SO}_{5}^{-}+\mathrm{SO}_{3}{ }^{2-} \rightarrow \mathrm{SO}_{4}^{-}+\mathrm{SO}_{4}{ }^{2-} \\
& \mathrm{SO}_{5}^{-}+\mathrm{SO}_{3}{ }^{2-} \rightarrow \mathrm{SO}_{3}^{-}+\mathrm{SO}_{5}{ }^{2-} \\
& \mathrm{SO}_{4}^{-}+\mathrm{SO}_{3}{ }^{2-} \rightarrow \mathrm{SO}_{4}{ }^{2-}+\mathrm{SO}_{3}{ }^{-}
\end{aligned}
$$

Any radical-radical reaction could terminate the chain; reaction (R24) is the most probable because $\mathrm{SO}_{5}^{-}$is the least reactive radical involved in the chain and is therefore present in the largest concentration. Caro's acid is produced by reaction (R13b) followed by equilibrium (E15).

Caro's acid is known to react with halide ions, e.g.,

$$
\mathrm{HSO}_{5}^{-}+\mathrm{Br} \rightarrow \mathrm{SO}_{4}^{2-}+\mathrm{HOBr} .
$$

This leads to the production of elemental bromine via

$$
\mathrm{HOBr}+\mathrm{Br}+\mathrm{H}^{+} \rightarrow \mathrm{Br}_{2}+\mathrm{H}_{2} \mathrm{O} .
$$

$\mathrm{Br}_{2}$ escapes to the gas phase where it is readily photolyzed to produce Br. At $298 \mathrm{~K}$, with a typical seawater ratio of $\mathrm{Cl}^{-}$to $\mathrm{Br}$, roughly equal amounts of $\mathrm{HOCl}$ and $\mathrm{HOBr}$ are produced by reactions (R2) and (R3). At $240 \mathrm{~K}$, production of $\mathrm{HOBr}$ predominates. Under these conditions, substantial amounts of $\mathrm{Cl}_{2}$ are not produced until the $\mathrm{Br}$ is exhausted. The data of Jobson et al. [1994] implies a gas phase $\mathrm{Br}$ to $\mathrm{Cl}$ ratio between 400:1 and 1200:1.

There is a much larger flux of gas phase $\mathrm{HO}_{2}$ than $\mathrm{OH}$ to the drops. Although $\mathrm{HO}_{2}$ and its conjugate base, $\mathrm{O}_{2}$; are not particularly strong oxidants in solution, they can form more strongly oxidizing free radicals by means of the reactions

$$
\begin{aligned}
& \mathrm{O}_{2}^{-}+\mathrm{O}_{3} \rightarrow \mathrm{O}_{3}^{-}+\mathrm{O}_{2} . \\
& \mathrm{O}_{3}^{-}+\mathrm{H}^{+} \rightarrow \mathrm{OH}+\mathrm{O}_{2} .
\end{aligned}
$$

Lelieveld and Crutzen [1991] have argued that this is the dominant source of $\mathrm{OH}$ in cloud drops. As pointed out by Zafiriou [1974] and discussed further in the following 
section, $\mathrm{OH}$ is rapidly and almost completely converted to $\mathrm{Br}_{2}^{-}$in seawater. Since $\mathrm{Br}_{2}^{-}$reacts rapidly with $\mathrm{SO}_{3}{ }^{2-}$ (reaction $(\mathrm{R} 20)$ and $\left[\mathrm{SO}_{3}{ }^{2-}\right]$ is very large at $p \mathrm{H} 7$ (nearly $1 / 2$ the alkalinity), virtually every $\mathrm{OH}$ produced in solution should initiate the free radical chain reaction.

The upper limit to the number of free radical chains initiated by reaction (R11) is given by the flux of $\mathrm{HO}_{2}$ to the drop. Since sea-salt particle radii are much larger than mean free paths in air, the flux is determined primarily by gas phase diffusion [Schwart, 1986]. Let $\phi$ be the rate of transport of $\mathrm{HO}_{2}$ per unit liquid phase volume. Then if the partial pressure of $\mathrm{HO}_{2}$ is $P_{\mathrm{HO} 2}$ and the particle radius is $a, \phi$ is given by [Schwark, 1986]

$$
\phi=\frac{3 D_{G} P_{H O_{2}}}{a^{2} R T}
$$

where $D_{\mathrm{G}}$ is the gas phase diffusion coefficient. For trace gases in air, $D_{\mathrm{G}}$ in units of $\mathrm{cm}^{2} \mathrm{~s}^{-1}$ may be estimated by

$$
D_{G}=(0.200)\left(\frac{T}{298}\right)^{1.75}\left(\frac{29}{M_{W}}\right)^{0.5}
$$

For $1 \mathrm{ppt}$ of $\mathrm{HO}_{2}$ at $240 \mathrm{~K}$ with $a^{2}=2.0 \times 10^{-8} \mathrm{~cm}^{2}$, we have $\phi=1.0 \times 10^{-6} \mathrm{M} \mathrm{s}^{-1}$. For a steady state between this source and reaction (R11), if the drop is in equilibrium with 40 $\mathrm{ppb}$ of gas phase $\mathrm{O}_{3}$, we have $\left[\mathrm{O}_{2}^{-}\right]=4.5 \times 10^{-7} \mathrm{M}$.

In addition to undergoing reaction ( $\mathrm{R} 11), \mathrm{HO}_{2}(\mathrm{aq})$ may either reevaporate from the drop or be consumed by reaction (R26). The characteristic time for reaction of $\mathrm{O}_{2}$ via (R11) is $0.45 \mathrm{~s}$. Since this is much shorter than the gas phase mass transport characteristic time, $\left(H_{\mathrm{HO}_{2}} P_{\mathrm{HO}} / \phi\right)$, of $180 \mathrm{~s}$, the $\mathrm{HO}_{2}$ radicals do not reevaporate. This gas phase mass transport time is for diffusion of material from the drops, not from the gas phase to the drops. It therefore depends on gas solubility. The solubility is calculated using the effective Henry's law constant, $H$; this includes the acid dissociation, equilibrium (E16). Since the time for reaction is much longer than the $0.7 \mathrm{~ms}$ characteristic time for liquid phase diffusion (Appendix $\mathrm{B}$ ), the $\mathrm{OH}$ radicals are produced uniformly throughout the drop. At $p H 7$, $\left[\mathrm{HO}_{2}\right]$ is less than $1 \%$ of $\left[\mathrm{O}_{2}^{-}\right]$. The resulting characteristic time for reaction of $\mathrm{O}_{2}^{-}$via reaction $(\mathrm{R} 26)$ is $6.5 \mathrm{~s}$. Thus as long as the $p \mathrm{H}$ is high, over $90 \%$ of the $\mathrm{HO}_{2}$ radicals that enter the drop undergo reaction (R11) and the number of free radical chains initiated is near the upper limit.

The alkalinity of the drop determines how much S(IV) can be oxidized before the $p \mathrm{H}$ drops. The amount of Caro's acid produced is determined by the alkalinity and the competition between reaction (R13b) and reactions (R13a) and (R1). At $25^{\circ} \mathrm{C}, \mathbf{k}_{13 \mathrm{~b}} / k_{13 \mathrm{a}}=0.41$ [Deister and Wameck, 1990]. Also, ozone oxidation tends to dominate over the free radical mechanism [Chameides and Stelson, 1992]. Thus the yield of Caro's acid is only about $4 \%$ of $\mathrm{H}_{2} \mathrm{SO}_{4}$. However, the yield may be substantially different at lower temperatures. The activation energies for reactions (R13b) and (R13a) estimated in Appendix A yield $k_{13 \mathrm{~b}} / k_{13 \mathrm{a}}=11$ at $240 \mathrm{~K}$. Thus the chain reaction might produce mostly Caro's acid at $240 \mathrm{~K}$.
The ratio of the yield of Caro's acid to sulfate produced by reaction (R1) is given by

$$
\frac{\left[\mathrm{H}_{2} \mathrm{SO}_{5}\right]}{\left[\mathrm{H}_{2} \mathrm{SO}_{4}\right]}=\frac{k_{13 b}\left[\mathrm{SO}_{5}\right]}{k_{1}\left[\mathrm{O}_{3}\right]}
$$

If reaction (R24) is the major chain termination reaction, the resulting steady state $\left[\mathrm{SO}_{s}^{-}\right]$is

$$
\left[S O_{5}\right]=\sqrt{\frac{\phi}{2 k_{24}}}
$$

At $240 \mathrm{~K}$ this yields $\left[\mathrm{SO}_{5}^{-}\right] \approx 6.0 \times 10^{-8} \mathrm{M}$ and $\left[\mathrm{H}_{2} \mathrm{SO}_{5}\right] /$ $\left[\mathrm{H}_{2} \mathrm{SO}_{4}\right] \approx 1.0$. Thus up to one third of the alkalinity could be converted to Caro's acid. Since the calculated [ $\left.\mathrm{SO}_{5}{ }^{-}\right]$is smaller than $\left[\mathrm{O}_{2}{ }^{-}\right]$, reaction $(\mathrm{R} 25)$ is the dominant sink if it has a rate constant that is comparable to or larger than that of reaction (R24). Unfortunately, the rate constant for reaction (R25) has not been measured.

The Caro's acid produced by reaction (R13b) will not necessarily oxidize halide ions. Caro's acid is also known to oxidize S(IV) via

$$
\mathrm{HSO}_{5}^{-}+\mathrm{SO}_{3}^{2-} \rightarrow \mathrm{H}^{+}+2 \mathrm{SO}_{4}^{2-} .
$$

This reaction is faster than ( $\mathrm{R} 3$ ) and, at $p \mathrm{H}=7$ the concentrations of $\mathrm{SO}_{3}{ }^{2-}$ and $\mathrm{Br}$ are comparable. However, once the $p \mathrm{H}$ drops, reaction (R4) ceases to be effective; furthermore the corresponding reaction with $\mathrm{HSO}_{3}{ }^{-}$is much slower [Betterton and Hoffman, 1988]. To evaluate the effect of (R4), we must compare the lifetime of $\mathrm{HSO}_{s}$.

$$
\tau\left(\mathrm{HSO}_{5}\right)=\frac{1}{\mathrm{k}_{12}\left[\mathrm{SO}_{3}^{2}\right]}
$$

to the lifetime of $\mathrm{SO}_{3}{ }^{2}$,

$$
\tau\left(S \mathrm{O}_{3}^{2}\right)<\frac{1}{k_{136}\left[S O_{5}^{-}\right]}
$$

For the conditions assumed here, these lifetimes are 11 and $12 \mathrm{~s}$, respectively. Reaction with $\mathrm{O}_{3}$ makes the latter lifetime smaller. Thus although a significant fraction of the Caro's acid should react by (R4), a large part of the alkalinity could still be in the form of Caro's acid at the time the $p \mathrm{H}$ drops. Since $\mathrm{A}=2.8[\mathrm{Br}]$ and because of reaction (R6), less than $20 \%$ of the alkalinity needs to be converted to Caro's acid in order to release all the $\mathrm{Br}$ from the drop.

At $240 \mathrm{~K}$ with $[\mathrm{Br}]=4.7 \times 10^{-3} \mathrm{M}$, the lifetime of Caro's acid is 4.2 hours; this is much shorter than the particle lifetime. The characteristic times for the $\mathrm{HOBr}$ produced are (in milliseconds) for liquid phase diffusion (Appendix B), 0.7; gas phase diffusion, 0.09; chemical reaction (R6), 0.04. Thus the rate of escape from the drop is determined by the rate of liquid phase diffusion and most of the HOBr oxidizes $\mathrm{Br}$ instead of escaping from the drop. 
Models of Arctic ozone depletion [McConnell et al., 1992; Fan and Jacob, 1992] show concentrations of BrO up to $30 \mathrm{ppt}$. In solution, BrO is thermodynamically capable of oxidizing $\mathrm{SO}_{3}^{2-}$ [Stanbury, 1989],

$$
\mathrm{BrO}+\mathrm{SO}_{3}{ }^{2-} \rightarrow \mathrm{BrO}^{-}+\mathrm{SO}_{3}^{-} .
$$

If this reaction proceeds at a fast enough rate to compete with reevaporation of $\mathrm{BrO}$, then it should greatly enhance the production of Caro's acid and potentially cause the release of $\mathrm{Br}$ from the aerosol to be autocatalytic.

Another potential means of initiating the chain reaction is the oxidation of $\mathrm{SO}_{3}{ }^{2-}$ by $\mathrm{NO}_{2}$. Although the mechanism of this reaction is unknown, the electron transfer reaction (R22) is thermodynamically feasible [Stanbury, 1989]. With $\left[\mathrm{SO}_{3}{ }^{2}\right]=A / 2$, the lifetime of liquid phase $\mathrm{NO}_{2}$ with respect to this reaction is $\tau_{R}=12 \mu \mathrm{s}$. Since this is much smaller than the characteristic time for liquid phase diffusion, $\tau_{\mathrm{LD}}=700 \mu \mathrm{s}$, the rate is controlled by the characteristic time for combined reaction and diffusion [Schwart, 1986]; this is $\left(5 \tau_{\mathrm{LD}} \tau_{\mathrm{R}} / 3\right)^{1 / 2}=120 \mu \mathrm{s}$. Because of the low solubility of $\mathrm{NO}_{2}$ the characteristic time for gas phase diffusion from the drop is only $0.10 \mu \mathrm{s}$; thus the surface of the drop is in equilibrium with gas phase $\mathrm{NO}_{2}$. With a gas phase $\mathrm{NO}_{2}$ mixing ratio of $30 \mathrm{ppt}$, reaction (R22) initiates $2 \%$ as many chains as $1 \mathrm{ppt}$ of $\mathrm{HO}_{2}$. Thus this reaction is not significant after sunrise.

However, reaction (R22) may be important as a dark reaction. Because the chain termination is second order, the rate of free radical oxidation goes as the square root of the rate of initiation. Before sunrise, with $\mathrm{NO}_{2}$ as the only significant gas phase radical, the rate of Caro's acid production is one seventh of that estimated above for $\mathrm{HO}_{2}$ on the basis of equation (5). This is sufficient to release about $40 \%$ of the initial $\mathrm{Br}$. As a result, a reservoir of gas phase $\mathrm{Br}$ could accumulate before polar sunrise. Some $\mathrm{HO}_{2}$ may be present at night because of the reaction of $\mathrm{O}_{3}$ with olefins; $5 \times 10^{5}$ molecules $\mathrm{cm}^{-3}$ of $\mathrm{HO}_{2}$ are required to equal reaction (R22) in initiating free radical chains.

Another possible source of liquid phase radicals is the reaction of $\mathrm{O}_{3}$ with $\mathrm{H}_{2} \mathrm{O}_{2}$ (R10). If the particles are in equilibrium with the gas phase, the ratio of radical production from reaction (R10) to that from reaction (R11) is

$$
\frac{2 k_{10} H_{H 2 O 2} K_{17} P_{B Z O 2}}{k_{11} H_{H O 2} K_{18} P_{H O 2}}=4.5 \times 10^{-10} \frac{P_{B 2 O 2}}{P_{H O 2}}
$$

Mass transfer effects increase this ratio by about a factor of 400; nevertheless, reaction (R10) is insignificant in comparison to reaction (R11), even in the dark.

The production of Caro's acid is much less efficient at higher temperatures. First, higher temperatures reduce the solubility of $\mathrm{O}_{3}$ and therefore increase the lifetime of $\mathrm{O}_{2}$ : For example, at $298 \mathrm{~K}$ with $40 \mathrm{ppb}$ of ozone the lifetime of $\mathrm{O}_{2}^{-}$with respect to reaction (R11) is $1.3 \mathrm{~s}$. The longer lifetime and reduced solubility of $\mathrm{HO}_{2}$ increase the likelihood of $\mathrm{HO}_{2}$ reevaporation from the drop. $\left[\mathrm{O}_{2}{ }^{-}\right]$and therefore the effect of reactions (R26) and (R25) also increase. At $298 \mathrm{~K}$, with $20 \mathrm{ppt}$ of $\mathrm{HO}_{2}$, as might be encountered in the marine boundary layer, reaction (R11) gives a steady state $\left[\mathrm{O}_{2}^{-}\right]$of $3.0 \times 10^{-5} \mathrm{M}$. At $p \mathrm{H} 7$ the resulting lifetime of $\mathrm{O}_{2}^{-}$with respect to reaction (R26) is then just $33 \mathrm{~ms}$; thus this becomes the dominant sink. As a result, only about $15 \%$ of the $\mathrm{HO}_{2}$ radicals arriving at the drop are converted to $\mathrm{OH}$ and the rate of initiation of radical chains is only about a factor of 2 larger than with 1 ppt of $\mathrm{HO}_{2}$ at $240 \mathrm{~K}$. Furthermore, the efficiency of chain propagation is reduced at higher temperatures because of reduced solubility of $\mathrm{SO}_{2}$. Thus the rate of Caro's acid production by reaction (R13b) is not changed very much by increased temperature. However, the large temperature dependencies of reactions (R13a) and (R1) result in a faster rate of $\mathrm{SO}_{4}{ }^{2-}$ production and therefore a smaller yield of Caro's acid. In addition, the loss of Caro's acid by means of reaction (R4) is greater at higher temperatures. During the Arctic summer, $\mathrm{SO}_{2}$ is much lower than in winter; this further reduces the efficiency of the chain reaction. As a result this mechanism is probably not important in either the Arctic summer or the global marine boundary layer.

\section{Release of Bromine by Free Radical Reactions}

When the alkalinity is fully converted to sulfate, the $p \mathrm{H}$ drops sharply. The calculations in the previous section indicate that the Caro's acid produced during the high $p \mathrm{H}$ interval may or may not be sufficient to oxidize all the sea-salt $\mathrm{Br}$. Under moderate $\mathrm{pH}$ conditions, $\mathrm{Br}_{2}$ may be produced by radical-radical reactions in solution.

The $\mathrm{OH}$ radical has an extremely short lifetime in seasalt solutions because it reacts rapidly with halide ions. This proceeds via HOX' radicals (equilibria E20 and E21). For $\mathrm{HOCl}^{-}$the acid-catalyzed reaction (R16) dominates over unimolecular dissociation for $p \mathrm{H}$ less than about 9; for $\mathrm{HOBr}$ the unimolecular reaction (R14) dominates (R15) above $p H 4$. At $298 \mathrm{~K}$ the equilibrium amounts of $\mathrm{HOBr}$ and $\mathrm{HOCl}$ in sea-salt solutions are roughly equal. Since the diffusion-controlled rate constants for (R16) and (R15) are virtually identical, roughly equal amounts of $\mathrm{Cl}$ and $\mathrm{Br}$ form if the $p \mathrm{H}$ is below 4. Above this $p \mathrm{H}$, production of $\mathrm{Br}$ dominates, as discussed by Zafiriou [1974]. At low temperatures, $\mathrm{HOBr}$ is favored and the formation of $\mathrm{Br}$ predominates over $\mathrm{Cl}$ for all $\mathrm{pH}$ even if reaction (R14) is very slow. Of course, depletion of $\mathrm{Br}$ from the particle eventually causes the formation of $\mathrm{Cl}$ to be favored.

Halogen atoms are rapidly converted to dihalogen radicals by equilibria (E22) and (E23). Both $\mathrm{Cl}_{2}{ }^{-}$and $\mathrm{Br}_{2}$. rapidly oxidize S(IV) [Shoute et al., 1991]. However, at low $p H$, where $S(I V)$ concentrations are low, radicalradical reactions may predominate. Although $\mathrm{Br}_{2}$ - oxidizes superoxide

$$
\mathrm{Br}_{2}^{-}+\mathrm{O}_{2}^{-} \rightarrow 2 \mathrm{Br}+\mathrm{O}_{2}
$$

it reduces $\mathrm{HO}_{2}$

$$
\mathrm{Br}_{2}^{-}+\mathrm{HO}_{2} \rightarrow \mathrm{Br}_{2}+\mathrm{HO}_{2}^{-}
$$

This may liberate $\mathrm{Br}_{2}$ from sea-salt. In contrast, $\mathrm{Cl}_{2}$ oxidizes both $\mathrm{O}_{2}^{-}$and $\mathrm{HO}_{2}$. These reactions prevent the buildup of $\mathrm{Cl}_{2}^{-}$or $\mathrm{Br}_{2}^{-}$to levels where significant halogen molecule production can result from self-reaction. 
Both the rate constant and products of reaction (R28) have been questioned by Wagner and Strehlow [1987]. However, other rate constants resulting from their experiments are inconsistent with established values. This may be due to their neglect of the reaction of $\mathrm{HO}_{2}$ with $\mathrm{Br}_{2}$ in the complex mechanism used to fit the rate constants; if so, Wagner and Strehlow's conclusions on reaction (R28) are probably not valid.

To evaluate the production of $\mathrm{Br}_{2}$ by reaction ( $\left.\mathrm{R} 28\right)$, we need an estimate of the $\mathrm{pH}$. At $240 \mathrm{~K}$ in the presence of $50 \mathrm{ppt}$ of $\mathrm{H}_{2} \mathrm{O}_{2}$, the dominant $\mathrm{S}(\mathrm{IV})$ oxidation reaction is (R9) if the $p H$ is below 5.9. Eventually, a steady state $p H$ is established with the production of acidity by $\mathrm{S}$ (IV) oxidation being balanced by the evaporation of $\mathrm{HCl}$ from the drop:

$$
\mathrm{H}^{+}+\mathrm{Cl}^{-} \rightarrow \mathrm{HCl}(\mathrm{g})
$$

The rate constant, $k_{\mathrm{HC}}$, for (R29) can be obtained from the requirement that at equilibrium the fluxes of $\mathrm{HCl}$ to and from the drop must be equal. If the drop radius is $a$ and the gas phase diffusion coefficient is $D_{\mathrm{HCl}}$ we have for the rate constant of reaction ( $R 29)$

$$
k_{B C l}=\frac{3 D_{B C l}}{a^{2} R T K_{6}}
$$

Setting the rate of reaction (R29) equal to twice the rate of S(IV) oxidation, we obtain a steady state $\mathrm{pH}$ of 3.3 for the conditions considered here. Uptake of $\mathrm{HNO}_{3}$ will lower the $p \mathrm{H}$ and increase the rate of $\mathrm{Br}_{2}$ production estimated in the following. However, particle $\mathrm{NO}_{3}^{-}$is much lower than particle $\mathrm{SO}_{4}{ }^{2-}$ during the Arctic winter and spring [Bottenheim et al., 1990].

At $240 \mathrm{~K}$ with $1 \mathrm{ppt}$ of $\mathrm{HO}_{2}$ and $40 \mathrm{ppb}$ of $\mathrm{O}_{3}$, the major aqueous phase sink of $\mathrm{HO}_{2}$ is reaction (R26) rather than (R11) if the pH is less than 5.8. Reaction ( $R 26)$ is faster than reevaporation for $p H$ greater than 2.9. Treating ( $R 26)$ as the sole $\mathrm{HO}_{2}$ sink, at steady state we have

$$
\left[O_{2}^{-}\right]=\sqrt{\frac{\phi K_{16}}{2 k_{26}\left[H^{+}\right]}}
$$

with $\phi$ given by equation (3). At $p H 3.3$ this yields $\left[\mathrm{O}_{2}^{-}\right] \approx 2 \times 10^{-8} \mathrm{M}$. The rate of $\mathrm{Br}_{2}$ formation is equal to the rate of reaction ( $\mathrm{R} 11$ ) times the branching ratio between reactions ( $R 27$ ) and (R28). Thus

$$
\frac{d\left[B r_{2}\right]}{d t}=k_{11}\left[O_{2}\right]\left[O_{3}\right] \frac{k_{28}\left[H^{+}\right]}{k_{28}\left[H^{+}\right]+k_{27} K_{16}}
$$

This rate is a maximum at $p H 4.5$, independent of $\phi$ and $\mathrm{O}_{3}$. At $\mathrm{p} 3.3$ this rate is about $4 \times 10^{-8} \mathrm{M} \mathrm{s}^{-1}$ and all the $\mathrm{Br}$ in a sea-salt particle could be oxidized in about 16 hours. At $p \mathrm{H} 4.5$ this rate is $1 \times 10^{-7} \mathrm{M} \mathrm{s}^{-1}$ and the $\mathrm{Br}$ could be oxidized in about 6 hours.

Some of the $\mathrm{Br}$ released is converted to $\mathrm{HBr}$ and should return to the particle phase. Most of the $\mathrm{HBr}$ condenses on the highly acidic fine sulfate particles since these have most of the aerosol surface area [Stacbler et al., 1994]. Li et al. [1990] have observed that most of the particulate $\mathrm{Br}$ is in the fine sulfate particles. At the very low $p H$ of the sulfate particles, this mechanism is insignificant.

Under global marine boundary layer conditions (298 K, 20 ppt $\mathrm{HO}_{2}, 20 \mathrm{ppb} \mathrm{O}, 50 \mathrm{ppt} \mathrm{SO}_{2}$ ) the $\mathrm{pH}$ is controlled by the balance between (R29) and (R1); this gives a steady state $p H$ of 6.4 . Under these conditions, equation (10) is valid for $p H$ between 3.9 and 9.2 ; this yields $\left[\mathrm{O}_{2}^{-}\right] \approx 2 \times 10^{-6} \mathrm{M}$. However, the rate of production of $\mathrm{Br}_{2}$ is much less than the rate of reaction (R11) due to the competition between ( $R 27)$ and ( $R 28$ ). The resulting $\mathrm{Br}_{2}$ formation rate is $1 \times 10^{-8} \mathrm{Ms}^{-1}$ so that the $\mathrm{Br}$ lifetime is about 60 hours. Additional acidification of the particles by $\mathrm{HNO}_{3}$ uptake increases the $\mathrm{Br}_{2}$ formation rate according to equations (10) and (11). The maximum $\mathrm{Br}_{2}$ production rate at $p H 4.5$ gives a $\mathrm{Br}$ lifetime of 12 hours. Rancher and Kritz [1980] have reported that a large fraction of the particulate sea-salt $\mathrm{Br}$ is converted to gas phase inorganic $\mathrm{Br}$ in the course of 1 day.

\section{Autocatalytic Release of Halogens}

In addition to these primary release mechanisms, there are possible autocatalytic cycles for the release of bromine from sea-salt. Gas phase $\mathrm{Br}$ atoms are converted into $\mathrm{BrO}$ via

$$
\mathrm{Br}+\mathrm{O}_{3} \rightarrow \mathrm{BrO}+\mathrm{O}_{2} .
$$

As noted above, BrO radicals may initiate free radical reactions in the particle phase. Also, gas phase $\mathrm{Br}$ is converted into either $\mathrm{HBr}$ by reaction with hydrocarbons or $\mathrm{HOBr}$ via

$$
\mathrm{BrO}+\mathrm{HO}_{2} \rightarrow \mathrm{HOBr}+\mathrm{O}_{2} \text {. }
$$

If $\mathrm{HOBr}$ returns to the sea-salt particles, it can oxidize $\mathrm{Br}$ to $\mathrm{Br}_{2}$ via reaction (R6). This reaction may also occur on suspended ice crystals or on the snowpack; the corresponding reaction with $\mathrm{Cl}$ has been observed [Abbatt and Molina, 1992]. The result is the conversion of one active $\mathrm{Br}(\mathrm{HOBr})$ into two active $\mathrm{Br}$ atoms $\left(\mathrm{Br}_{2}\right)$. If more than half the $\mathrm{Br}$ atoms released are converted to $\mathrm{HOBr}$, this results in an amplification of the photochemically active $\mathrm{Br}$ in the air mass. If the production of $\mathrm{HBr}$ exceeds $\mathrm{HOBr}$, then not all the $\mathrm{HBr}$ is recycled and $\mathrm{Br}$ gradually accumulates in this inactive form unless there is another means of recycling $\mathrm{HBr}$. Although the primary $\mathrm{Br}_{2}$ production mechanisms are relatively slow, they may be important in maintaining active $\mathrm{Br}$ levels if the yield of $\mathrm{HOBr}$ is slightly less than the yield of $\mathrm{HBr}$.

Processes that favor the production of $\mathrm{HBr}$ instead of $\mathrm{HOBr}$ are the conversion of $\mathrm{BrO}$ back to $\mathrm{Br}$ atoms

$$
\mathrm{BrO}+\mathrm{BrO} \rightarrow 2 \mathrm{Br}+\mathrm{O}_{2}
$$

or

$$
\mathrm{BrO}+\mathrm{NO} \rightarrow \mathrm{Br}+\mathrm{NO}_{2}
$$


and the photolysis of $\mathrm{HOBr}$

$$
\mathrm{HOBr}+\mathrm{h} v \rightarrow \mathrm{Br}+\mathrm{OH} .
$$

These reactions are essential parts of the catalytic cycle that destroys $\mathrm{O}_{3}$. If reaction (R6) is the main means of recycling active $\mathrm{Br}$, then the efficiency of the recycling should be very sensitive to the details of the gas phase chemistry.

Reactions (R32) and (R34) are much slower for chlorine than for bromine, as a result the autocatalytic cycle should be much more efficient for $\mathrm{Cl}$. Also, in the marine troposphere there is much more $\mathrm{HO}_{2}$ than in the Arctic. This favors the production of $\mathrm{HOCl}$ and therefore shifts the cycle toward the autocatalytic mode. In the global marine atmosphere, where the primary reactions discussed here are not very efficient, these cycles may be critical to the formation of significant active $\mathrm{Cl}$ concentrations. Evidence that significant active $\mathrm{Cl}$ is produced in the marine boundary layer has been given by Keene et al. [1990] and Pszenny et al. [1993]. However, the rate of Cl release by reaction (R5) is less than the rate of release by (R29). At $273 \mathrm{~K}$ about $2 \mathrm{ppb}$ of $\mathrm{HOCl}(\mathrm{g})$ is needed for (R5) to release $\mathrm{Cl}$ as fast as (R29), while at $298 \mathrm{~K}$ over 50 $\mathrm{ppb}$ of $\mathrm{HOCl}$ is needed. Thus this mechanism does not explain the high rate of $\mathrm{Cl}$ release from sea-salt.

\section{Conclusions}

Under conditions encountered during polar sunrise, bromine molecules may be released from sea-salt aerosol particles on a timescale of a few hours by either the production of Caro's acid in the free radical oxidation of $\mathrm{S}(\mathrm{IV})$ at high $\mathrm{pH}$ or the direct free radical oxidation of bromide at moderate $p H$. These mechanisms are capable of converting virtually all the sea-salt bromide into gas phase bromine. The former mechanism requires both low temperature and high $\mathrm{SO}_{2}$ concentrations; as a result it causes $\mathrm{Br}_{2}$ release only during the winter and early spring, as is observed. The latter mechanism could oxidize significant amounts of sea-salt $\mathrm{Br}$ in the global marine boundary layer. $\mathrm{HOCl}$ and $\mathrm{Cl}_{2}$ are only minor products of these reactions.

The evaluation of these mechanisms at low temperatures is very uncertain because of incomplete physicalchemical data. In particular, the yield of Caro's acid depends critically on the temperature dependence of the rate constant and branching ratio of the free radical oxidation of S(IV) via reactions (R13a) and (R13b). In addition, data are needed on the mechanism and temperature dependencies of reaction (R22), the possible occurrence of reactions (R20) and (R25), and the effect of ionic strength on these rate constants.

In addition to the primary release mechanisms, there are possible autocatalytic cycles that may enhance the release of bromine from sea-salt once some active bromine is formed. These are the initiation of liquid phase free radical chemistry by BrO supplied from the gas phase and the oxidation of bromide ions to elemental bromine by $\mathrm{HOBr}$ supplied from the gas phase. Evaluation of these processes will require coupling the appropriate liquid phase chemistry to a detailed model of the gas phase chemistry.

\section{Appendix A: Estimates of Temperature Dependencies}

Many of the equilibrium and rate constants used here have only been measured near room temperature. To estimate temperature dependencies, it is much better to use estimates of entropy changes rather than enthalpy changes; this is because entropies usually vary in a more systematic and predictable manner than enthalpies. Thus most of these estimates are made by estimating $\Delta S$ and then determining the value of $\Delta H$ required to give the correct rate or equilibrium constant at the temperature of measurement.

To estimate temperature dependencies for gas solubilities, entropies of solution were estimated by the method of Berdnikov and Bazhin [1970]. The solubilities of $\mathrm{HOCl}$, $\mathrm{HOBr}, \mathrm{Cl}_{2}$, and $\mathrm{Br}_{2}$ were calculated from thermodynamic data tabulated by Wagman et al. [1982] and by Benson [1976] (for $\operatorname{HOBr}(\mathrm{g})$ ). The origin and reliability of these data are not clear; in particular the quoted uncertainty ( $\pm 2 \mathrm{kcal} \mathrm{mol}^{-1}$ ) in $\Delta \mathrm{H}_{\mathrm{f}}{ }^{\circ}$ for $\mathrm{HOBr}(\mathrm{g})$ leads to a factor of 30 uncertainty in the solubility. The resulting $\mathrm{HOBr}$ solubility is only a little larger than the solubilities of $\mathrm{Br}$ and $\mathrm{Br}_{2}$; this amounts to assuming that $\mathrm{HOBr}$ is almost entirely nonpolar, with very little tendency to hydrogen bond with water. The larger solubility of $\mathrm{HOCl}$ must be due to hydrogen bonding; this should be less effective for $\mathrm{HOBr}$ since the $\mathrm{OH}$ bond is less polar, as indicated by the fact that $\mathrm{HOBr}$ is a weaker acid than $\mathrm{HOCl}$. Even the upper limit to the solubility of $\mathrm{HOBr}$ is smaller than the solubility of $\mathrm{HOCl}$. The calculated solubilities of $\mathrm{HOCl}$ are consistent with the experimental estimates of Hanson and Ravishankara [1991] for $\mathrm{H}_{2} \mathrm{SO}_{4}$ solutions.

For equilibria (E16) and (E17), temperature dependencies were obtained by using the observation that the entropies of dissociation of all uncharged acids are near $-11 R$ [Pitzer, 1937]. Equilibrium (E15) was assumed to have the same $\Delta \mathrm{S}$ as (E19).

Equilibria (E20) through (E23) all involve a neutral species combining with an ion to form an ion. From the arguments given by Pitzer [1937], we should expect reactant and product ions to have similar entropies of solution. If we consider a cycle consisting of removing the reactants to the gas phase, conducting the reaction in the gas phase, and returning the products to the solution, we see that $\Delta S_{R}$ for the solution reaction should be nearly equal to $\Delta S_{\mathrm{G}}$ for the gas phase reaction minus the entropy of solution of the neutral species, $\Delta S_{\mathrm{S}}$. Let $\Delta S_{\mathrm{N}}$ be the entropy change for the reaction of the corresponding gas phase neutral species. Then $\Delta S_{\mathrm{G}}$ differs from $\Delta S_{\mathrm{N}}$ only by the difference in the electronic entropies of the ions and the neutral species. The halide ions and the neutral molecules corresponding to the products have electronic entropies of zero. The halogen atoms have $S^{\circ}{ }_{\text {elec }} \approx R \ln 4$, from the ${ }^{2} P_{3 / 2}$ ground state. The molecular ions have $S^{\circ}$ elec $\approx R \ln 2$, from spin. Therefore we have for all of these reactions

$$
\Delta S_{R}=\Delta S_{N}+3 R \ln 2-\Delta S_{S}
$$

Using data from Benson [1976] we have $\Delta S_{\mathrm{N}} / R$ equal to $-13.5,-13.3,-12.9$, and -12.6 for reactions (E20), (E21), (E22), and (E23), respectively. From Berdnikov and 
Bazhin [1970] we have $\Delta S_{\mathrm{S}} / R$ equal to $10.1,10.1,11.6$, and 12.6 for the same reactions. We therefore find $\Delta S_{\mathrm{R}} / R$ equal to $-21.5,-21.3,-22.4$, and -23.1 for these reactions.

Electron transfer reactions generally have low activation energies, ranging from $<0$ to $35 \mathrm{~kJ} \mathrm{~mol}^{-1}$, but most often 5 to $10 \mathrm{~kJ} \mathrm{~mol}^{-1}$ [Alfassi et al., 1990; Huic and Clifton, 1990; Shoute et al., 1991; Huic et al., 1991]. In contrast to the usual rule cited above, most of the variation in the rates of these reactions is in the entropy, not the energy, of activation. Accordingly, reactions (R11), (R13b), (R19), (R22), (R26), (R27), (R28), (R17), (R18), and (R10) were all assumed to have activation energies of $10 \mathrm{~kJ} \mathrm{~mol}^{-1}$. For the diffusion controlled reactions (R12), (R16), and (R15) a reasonable activation energy is $17.5 \mathrm{~kJ} \mathrm{~mol}^{-1}$ [Huie and Clifton, 1990]; this arises from the temperature dependence of the viscosity of water.

Eigen and Kustin [1962] put forward a mechanism for reactions (R5) and (R6) in which HOX and $X \cdot$ are in rapid equilibrium with an adduct that undergoes a diffusion-controlled reaction with $\mathrm{H}^{+}$. The rapid equilibria are similar to those discussed above and therefore should have $\Delta S \approx-22 R$; this implies enthalpy changes of -21.3 $\mathrm{kJ} \mathrm{mol}{ }^{-1}$ for the $\mathrm{Cl}$ reaction and $-54.4 \mathrm{~kJ} \mathrm{~mol}^{-1}$ for the $\mathrm{Br}$ reaction. With an activation energy of $17.5 \mathrm{~kJ} \mathrm{~mol}^{-1}$ for the diffusion-controlled step, the activation energies for reactions (R5) and (R6) are $-3.8 \mathrm{~kJ} \mathrm{~mol}^{-1}$ and $-36.9 \mathrm{~kJ}$ $\mathrm{mol}^{-1}$, respectively. The rate constants at $293 \mathrm{~K}$ were calculated from the values reported by Eigen and Kustin for reactions (R7) and (R8) and the equilibrium constants measured by Connick and Chia [1959] and Liebhafsky $[1934,1939]$. These were combined with the above activation energies to obtain the values listed in Table 3 for reactions (R5) through (R8). The resulting small temperature dependence for reaction (R5) is consistent with the approximate results obtained by Hanson and Ravishankara [1991] in $\mathrm{H}_{2} \mathrm{SO}_{4}$ solutions at $263 \mathrm{~K}$.

The temperature dependence of reaction (R14) was estimated by assuming that the reverse reaction is diffusion limited $\left(1.3 \times 10^{10} \mathrm{M} \mathrm{s}^{-1}\right.$ at $\left.298 \mathrm{~K}\right)$, and by estimating the temperature dependence for the equilibrium constant $\left(3.2 \times 10^{4} \mathrm{M}\right.$ at $\left.298 \mathrm{~K}\right)$ as described above. This gives $\Delta S \approx 21.6 R$, greater than for reaction (E6) by the difference in the electronic entropies of $\mathrm{OH}$ and $\mathrm{Br}$.

Reaction (R13a) is an O atom transfer and might have an activation energy similar to the activation energy of 44 $\mathrm{kJ} \mathrm{mol}^{-1}$ for reaction (R1); this assumption was used in Table 3. However, one might also argue that the $A$ factor for this reaction should be similar to reactions (R2) and (R3). This assumption leads to an activation energy of only $5.0 \mathrm{~kJ} \mathrm{~mol}^{-1}$ for (R13a) and would cause this channel to be increasingly favored over (R13b) as the temperature drops. Reaction (R4) was assumed to have the same A factor as reactions (R2) and (R3). Reaction (R24) must proceed via a cyclic transition state. Since it is quite fast, it is likely that the A factor is not too different from the rate constant, so that the temperature dependence is small.

\section{Appendix B: Characteristic Time for Diffusion From a Drop}

The literature contains a variety of expressions for the characteristic time for liquid phase diffusion. There is no single, compelling way to define this for the reaction of a species entering a drop because the rate is never entirely controlled by liquid phase diffusion. However, if a species is produced uniformly throughout a drop at rate $S$ and escapes to the gas phase, there is a well defined liquid phase lifetime. This can be obtained by solving the steady state continuity equation

$$
S=-\frac{D_{L}}{r^{2}} \frac{\partial}{\partial r}\left(r^{2} \frac{\partial[A]}{\partial r}\right)
$$

subject to the boundary condition $[A]=0$ at the surface of the drop. This amounts to assuming that the escape from the drop is controlled only by liquid phase diffusion. The solution is

$$
[A]=\frac{S}{6 D_{L}}\left(a^{2}-r^{2}\right)
$$

If we integrate over the volume of the drop to obtain the average concentration and divide by the production term, $S$, we obtain for the average lifetime

$$
\tau_{L D}=\frac{a^{2}}{15 D_{L}}
$$

Acknowledgments: I thank J.C. McConnell for many helpful discussions. This work was supported by grants from the Natural Sciences and Engineering Research Council of Canada and the AES/NSERC Science Subvention Program. This is publication 93-3 of the Canadian Institute for Research in Atmospheric Chemistry.

\section{References}

Abbatt, J. P. D., and M. J. Molina, The heterogeneous reaction of $\mathrm{HOCl}+\mathrm{HCl} \rightarrow \mathrm{Cl}_{2}+\mathrm{H}_{2} \mathrm{O}$ on ice and nitric acid trihydrate: Reaction probabilities and stratospheric implications, Geophys. Res. Lett., 19, 461-464, 1992.

Alfassi, Z B., R. E. Huie, P. Neta, and L. C. T. Shoute, Temperature dependence of the rate constants for reaction of inorganic radicals with organic reductants, $J$. Phys. Chem., 94, 8800-8005, 1990.

Anlauf, K.G., R. Mickie, and N.B.A Trivett, Measurements of ozone during polar sunrise experiment 1992, J. Geophys. Res., 99, 25,345-25,353, 1994.

Barrie, L. A, J. W. Bottenheim, R. C. Schnell, P. J. Crutzen, and $R$. A Rasmussen, Ozone destruction and photochemical reactions at Polar Sunrise in the lower Arctic atmosphere, Nature, 334, 138-141, 1988.

Barrie, L. A., R. M. Staebler, D. Toom, B. Georgi, G. den Hartog, S. Landsberger, and D. Wu, Arctic aerosol sizesegregated chemical observations in relation to ozone depletion during Polar Sunrise 1992, J. Geophys. Res., 99, 25,439-25,451, 1994.

Benson, S. W., Thermochemical Kinetics, 2nd ed., WileyInterscience, New York, 1976.

Berdnikov, V. M., and N. M. Bazhin, Oxidation-reduction potentials of certain inorganic radicals in aqueous solutions, Russ. J. Phys. Chem. Engl. Transl, 44, 395-398, 1970.

Betterton, E. A. and M. R. Hoffmann, Oxidation of aqueous $\mathrm{SO}_{2}$ by peroxymonosulfate, J. Phys. Chem., 92, 5962-5965, 1988. 
Bottenheim, J. W., L. A. Barrie, E. Atlas, L. E. Heidt, H. Niki, R. A. Rasmussen, and P. B. Shepson, Depletion of lower tropospheric ozone during Arctic spring: The polar sunrise experiment 1988, J. Geophys. Res., 95, 18,55518,568, 1990.

Brimblecombe, P., and S. L. Clegg, The solubility and behaviour of acid gases in the marine aerosol, $J$. Atmos. Chem., 7, 1-18, 1988.

Chameides, W. L., and A. W. Stelson, Aqueous-phase chemical processes in deliquescent sea-salt aerosols: $A$ mechanism that couples the atmospheric cycles of $\mathrm{S}$ and sea-salt, J. Geophys. Res., 97, 20,565-20,580, 1992.

Connick, R. E., and Y.-T. Chia, The hydrolysis of chlorine and its variation with temperature, J. Am. Chem. Soc., 81, 1280-1284, 1959.

Deister, U., and P. Warneck, Photooxidation of $\mathrm{SO}_{3}{ }^{2}$ in aqueous solution, J. Phys. Chem., 94, 2191-2198, 1990.

Eigen, M., and $\mathrm{K}$. Kustin, The kinetics of halogen hydrolysis, J. Am. Chem. Soc., 84, 1355-1361, 1962.

Fan, S.-M., and D. J. Jacob, Surface ozone depletion in Arctic spring sustained by bromine reactions on aerosols, Nature, 359, 522-524, 1992.

Fortnum, D. H., C. J. Battaglia, S. R. Cohen, and J. O. Edwards, The kinetics of the oxidation of halide ions by monosubstituted peroxides, J. Am. Chem. Soc., 82, 778$782,1960$.

Hanson, D. R., and A. R. Ravishankara, The reaction probabilities of $\mathrm{ClONO}_{2}$ and $\mathrm{N}_{2} \mathrm{O}_{5}$ on 40 to $75 \%$ sulfuric acid solutions, J. Geophys. Res., 96, 17,307-17,314, 1991.

Hoffmann, M. R., On the kinetics and mechanism of oxida tion of aquated sulfur dioxide by ozone, Atmos. Environ., 20, 1145-1154, 1986.

Huje, R. E., and C. L. Clifton, Temperature dependence of the rate constants for reactions of the sulfate radical, $\mathrm{SO}_{4}$, with anions, J. Phys. Chem., 94, 8561-8567, 1990.

Huie, R. E., and P. Neta, Chemical behavior of $\mathrm{SO}_{3}$ and $\mathrm{SO}_{5}$ radicals in aqueous solutions, J. Phys. Chem., 88, 56655669, 1984.

Huie, R. E., and P. Neta, Kinetics of one-electron transfer reactions involving $\mathrm{ClO}_{2}$ and $\mathrm{NO}_{2}, J$. Phys. Chem., 90, 1193-1198, 1986.

Huie, R. E., and P. Neta, Rate constants for some oxidations of S(IV) by radicals in aqueous solutions, Atmos. Environ., 21, 1743-1747, 1987.

Huie, R. E., L. C. T. Shoute, and P. Neta, Temperature dependence of the rate constants for reaction of the carbonate radical with inorganic reductants, Int. J. Chem. Kinet., 23, 541-552, 1991.

Jacob, D. J., Chemistry of $\mathrm{OH}$ in remote clouds and its role in the production of formic acid and peroxymonosulfate, J. Geophys. Res., 91, 9807-9826, 1986.

Jobson, B. T., H. Niki, Y. Yokouchi, J. Bottenheim, F. Hopper, and $R$. Leaitch, Measurements of $\mathrm{C}_{2}-\mathrm{C}_{6}$ hydrocarbons during the Polar Sunrise 1992 Experiment, $J$. Geophys. Res., 99, 25,355-25,368, 1994.

Keene, W. C., A. A. P. Pszenny, D. J. Jacob, R. A Duce, J. N. Galloway, J. J. Schutlz-Tokos, H. Sievering, and J. F. Boatman, The geochemical cycling of reactive chlorine through the marine troposphere, Global Biogeochem. Cycles, 4, 407-430, 1990.

Klaning, U. K, K. Sehested, and J. Holcman, Standard Gibbs energy of formation of hydroxyl in aqueous solution. Rate constants for the reaction $\mathrm{ClO}_{2}^{-}+\mathrm{O}_{3}=\mathrm{O}_{3}^{-}+\mathrm{ClO}_{2}, \mathrm{~J}$. Phys. Chem., 89, 760-763, 1985.

Lelieveld, J., and P. J. Crutzen, The role of clouds in tropo spheric photochemistry, J. Atmos. Chem., 12, 229-267, 1991.

Li, S.-M., J.W. Winchester, J.D. Kahl, S.J. Oltmans, R.C. Schnell, and P.J. Sheridan, Arctic boundary layer ozone variations associated with nitrate, bromine, and meteorology: A case study, J. Geophys. Res., 95, 22,433-22,440, 1990.

Li, S.-M., Y. Yokouchi, L. A. Barrie, K. Muthuramu, P. B. Shepson, J. W. Bottenheim, W. T. Sturges, and S. Landsberger, Organic and inorganic bromine compounds and their compositions in the Actic Troposphere during Polar Sunrise, J. Geophys. Res., 99, 25,415-25,428, 1994.

Liebhafsky, H. A., The equilibrium constant of the bromine hydrolysis and its variation with temperature, J. Am. Chem. Soc., 56, 1500-1505, 1934.

Liebhafsky, H. A. The hydrolysis of bromine, The hydration of the halogens, The mechanism of certain halogen reactions, J. Am. Chem. Soc., 61, 3513-3519, 1939.

Lind, J. A, and G. L. Kok, Henry's law determination for aqueous solutions of hydrogen peroxide, methylhydroperoxide, and peroxyacetic acid, J. Geophys. Res., 91, 7889 7895, 1986.

McArdle, J. V., and M. R. Hoffmann, Kinetics and mechan ism of the oxidation of aquated sulfur dioxide by hydrogen peroxide at low $p, J$. Phys. Chem., 87, 5425-5429, 1983.

McConnell, J. C., G. S. Henderson, L. Barrie, J. Bottenheim, H. Niki, C. H. Langford, and E. M. Templeton, Photochemical bromine production implicated in Arctic boundary-layer ozone depletion, Nature, 355, 150-152, 1992.

McElroy, M. B., The aqueous oxidation of $\mathrm{SO}_{2}$ by $\mathrm{OH}$ radicals, Atmos. Environ., 20, 323-330, 1986.

Millero, F. J., J. P. Hershey, G. Johnson, and J.-Z Zhang, The solubility of $\mathrm{SO}_{2}$ and the dissociation of $\mathrm{H}_{2} \mathrm{SO}_{3}$ in $\mathrm{NaCl}$ solutions, J. Atmos. Chem., 8, 377-389, 1989.

Mozurkewich, M., Reactions of $\mathrm{HO}_{2}$ with free radicals, $J$. Phys. Chem., 90, 2216-2221, 1986.

Neta, P., R. E. Huje, and A B. Ross, Rate constants for reactions of inorganic radicals in aqueous solution, $J$. Phys. Chem. Ref. Data, 17, 1027-1284, 1988.

Pitzer, K. S., The heats of ionization of water, ammonium hydroxide, carbonic, phosphoric, and sulfuric acids. The variation of ionization constants with temperature and the entropy change with ionization, J. Am. Chem. Soc., 59, 2365-2371, 1937.

Pszenny, A. A. P., W. C. Keene, D. J. Jacob, S. Fan, J. R. Maben, M. P. Zetwo, M. Springer-Young, and J. N. Galloway, Evidence of inorganic chlorine gases other than hydrogen chloride in marine surface air, Geophys. Res. Lett., 20, 699-702, 1993.

Rancher, J., and M. A. Kritz, Diurnal fluctuations of Br and I in the tropical marine atmosphere, J. Geophys. Res., 85, 5581-5587, 1980.

Schwarz, H.A, and R.W. Dodson, Equilibrium between hydroxyl radicals and thallium(II) and the oxidation potentjal of OH(aq), J. Phys. Chem., 88, 3643-3647, 1984.

Schwartz, S. E., Gas and aqueous phase chemistry of $\mathrm{HO}_{2}$ in liquid water clouds, J. Geophys. Res., 89, 11,589-11,598, 1984.

Schwartz, S. E., Mass transport considerations pertinent to aqueous-phase reactions of gases in liquid-water clouds, in Chemistry of Multiphase Atmospheric Systems, edited by W. Jaeschke, Springer-Verlag, New York, 1986.

Schwartz, S. E., and W. H. White, Solubility equilibria of the nitrogen oxides and oxyacids in dilute aqueous solution, in Advances in Environmental Science and Engineering, vol 4, edited by J. R. Pfafflin and E. N. Ziegler, pp. 1-45, Gordon and Breach, New York, 1981.

Sehested, K, J. Holoman, and E. J. Hart, Rate constants and products of the reactions of $\mathrm{e}^{-}, \mathrm{O}_{2}$, and $\mathrm{H}$ with ozone in aqueous solutions, J. Phys. Chem., 87, 1951-1954, 1983.

Shoute, L. C. T., Z B. Alfassi, P. Neta, and R. E. Huie, Temperature dependence of the rate constants for 
reaction of dihalide and azide radicals with inorganic reductants, J. Phys. Chem., 95, 3238-3242, 1991.

Staebler, R. M., G. denHartog, B. Georgi, and T. Dusterdiek, Aerosol size distributions in Arctic haze during the Polar Sunrise Experiment 1992, J. Geophys. Res., 99, 25,429. $25,437,1994$.

Stachelin, J., and J. Hoigne, Decomposition of ozone in water: Rate of initiation by hydroxide ions and hydrogen peroxide, Environ. Sci. Technol, 16, 676-681, 1982.

Stanbury, D. M., Reduction potentials involving inorganic free radicals in aqueous solution, in Advances in Inonganic Chemistry, vol 33, edited by A. G. Sykes, pp. 69-138, Academic, San Diego, Calif., 1989.

Sutton, $\mathrm{H}$. C., and M. T. Downes, Reactions of the $\mathrm{HO}_{2}$ radical in aqueous solutions with bromine and related compounds, J. Chem. Soc. Faraday Trans. 1, 68, 1498-1507, 1972.

Wagner, I., and H. Strehlow, On the flash photolysis of bromide ions in aqueous solutions, Ber. Bunsenges. Phys. Chem., 91, 1317-1321, 1987.
Wagman, D. D., W. H. Evans, V. B. Parker, R. H. Schumm, I. Halow, S. M. Bailey, K L. Churney, and R. L. Nuttall, The NBS tables of chemical thermodynamic properties: Selected values for inorganic and $\mathrm{C}_{1}$ and $\mathrm{C}_{2}$ organic substances in SI units, J. Phys. Chem. Ref. Data, II, (Suppl. 2), 1982.

Wilhelm, E., R. Battino, and R. J. Wilcock, Low pressure solubility of gases in liquid water, Chem. Rev., 77, 219-262, 1977.

Zafiriou, O. C., Sources and reactions of $\mathrm{OH}$ and daughter radicals in seawater, J. Geophys. Res., 79, 4491-4497, 1974.

Michael Mozurkewich, Department of Chemistry, York University, 4700 Keele Street, North York, Ontario M3J 1P3, Canada E-mail Fs300530@SOL.YORKU.CA

(Received July 26, 1993; revised February 2, 1994; accepted February 3, 1994.) 